\title{
Uma reinvenção da diferença elitista: um Rotary Clube no Quênia de Mwai Kibaki ${ }^{1}$
}

\author{
Dominique Connan
}

\begin{abstract}
Resumo: A pesquisa etnográfica realizada entre 2008 e 2011 no Langata Rotary Club em Nairobi descreve a sociabilidade profissional, organizada em torno das reuniões semanais e dos eventos de caridade, das elites quenianas que se apropriam das representações globalizadas do sucesso econômico e social. A comunidade inter-regional do Rotary mostra a forma como as aspirações individuais de sucesso econômico, o reconhecimento social e a autoestima são combinadas com a promoção dos mantras da "boa governança" e da liberalização do Quênia. Os rotarianos têm um relacionamento paradoxal com o Estado, evitam a concorrência política e seus excessos e imitam suas práticas de legitimação: a burocracia, a tributação e, por meio da filantropia, o serviço público. A pesquisa, portanto, consegue mostrar o mais próximo possível, desde a intimidade de círculos de sociabilidade elitista, até a tradução para a vida quotidiana dos "jogos simbólicos de importação e exportação", através dos quais se legitima esse segmento das classes dominantes.
\end{abstract}

\author{
Plano do artigo \\ 1. A sociabilidade de uma geração de elite \\ 2. O profissional como um tipo de homem \\ 3. A forma de um evangelismo anti-político
}

\begin{abstract}
Sobre o autor
Dominique Connan

Doutor em Ciência Política pela Universidade Paris 1 (2014) e Doutor em História pelo Instituto Universitário Europeu de Florença (2015). Atualmente é Assistente Temporário de Educação e Pesquisa (ATER) do Departamento de Ciência Política da Universidade de Nice. O seu trabalho centra-se na sociabilidade das elites na África.

dominique.connan@gmail.com
\end{abstract}

\footnotetext{
1 Tradução livre de Ana Vanali. Texto original «Une réinvention de la différence élitaire : un Rotary Club dans le Kenya de Mwai Kibaki», Critique internationale, vol. 73, № 4, 2016, p. 133-155. Disponível em https://www.cairn.info/revue-critiqueinternationale-2016-4-page-133.htm. Acesso 25.outubro.2017. Autorização para a publicação da tradução cedido por Catherine Burucoa, responsável da Revista Critique Internationale (Sciences Po, Centre de Recherches Internationales) no dia 15 de novembro de 2017.
} 


\title{
Uma reinvenção da diferença elitista: um Rotary Club no Quênia de Mwai Kibaki
}

\author{
Dominique Connan
}

Em 2001, o arquiteto Edward G. Mugo decide com seu primo Alex Nyaga Mugo fundar um Rotary Club em seu bairro, em Langata, no sudeste de Nairobi ${ }^{2}$. Ambos eram jovens empresários bem-sucedidos nos negócios: aos 34 anos, Edward, formado pela Universidade de Nairobi, administra um escritório de arquitetura com filiais em Mombasa e Kigali, em Ruanda. Dois anos mais novo, Alex Nyaga se formou Alimentação Empresarial na Escola Internacional de Hotelaria des Roches, na Suíça. Ele acaba de criar com fundos familiares uma empresa de limpeza da qual ele assumiu a direção. Os Mugo é uma família abastada, instalada em Nairobi por duas gerações: o pai de Alex Nyaga, Harry Mugo, membro de longa data do Rotary Club de Nairobi Norte, é um topógrafo, ou seja, um economista da construção (agrimensor de quantidade). Depois de ter trabalhado em várias empresas públicas, co-fundou nos anos 1990, uma das maiores empresas topográficas do país, a GIMCO.

Então, foi em 2001 que Harry Mugo foi encarregado pelo Rotary de apoiar o lançamento de um novo clube em Nairobi. Em seu conselho, além de Edward Mugo e Alex Nyaga, juntava-se cerca de quinze pessoas, a maioria delas velhos camaradas do ensino médio ou da Universidade de Nairobi, bem como alguns com relações profissionais. No ano seguinte, o Rotary Club de Langata é oficialmente fundado. Ele se torna rapidamente um dos clubes mais movimentados de Nairobi. Seus levantamentos de fundos, seus projetos e seu dinamismo são citados regularmente como exemplos pelos outros rotarianos. Hoje, conta com cerca de 60 membros, que se reúnem todas as noites de quinta-feira nas instalações do Nairobi Club, um dos clubes de membros mais exclusivos da capital do Quênia ${ }^{3}$.

\footnotetext{
2 Nota da tradutora: Nairobié a capital, a cidade mais populosa e o principal centro financeiro, econômico, corporativo e cultural do Quênia. É a maior cidade da África Oriental.

${ }^{3}$ De outubro de 2008 a dezembro de 2011, segui em particular o Rotary Club de Langata e seus membros. Durante esses três anos, participei de umas sessenta reuniões, nas quintas-feira à noite às 19 horas no Nairobi Club. Além disso, segui seus membros em vários eventos, alguns deles organizados no quadro do Rotary, como torneios de golfe de caridade, os dias de família em restaurantes ou hotéis, dentre outros, respondendo aos convites de alguns para participar da missa dominical na Capela de Nairobi, aos torneios de golfe organizados por um deles dentre daqueles que ocupavam cargos oficiais no Vet Lab Golf Club em Nairobi. Eu também segui, entre duas ou dez reuniões, os clubes de Nairobi Norte, Milimani, Nairobi East, Muthaiga, Parklands, Westlands, Utumishi, Karen, Nairobi Central e Mashariki entre duas e dez vezes, bem como indo também aos jantares nesses mesmos clubes, noites festivas onde, todos os anos, um escritório e seu presidente passava o poder para o próximo. Eu finalmente fui a eventos organizados coletivamente por esses clubes: duas vezes em um jantar de reconhecimento Paul Harris, onde os principais doadores quenianos da Fundação Rotariana do Quênia são celebrados anualmente, e uma vez para um café da manhã no Rotary Corporate, cujo objetivo era trazer para o Rotary os chefes e executivos escolhidos pelo convite.
} 
Criado em 1905 nos Estados Unidos por um advogado de Chicago, Paul Harris ${ }^{4}$, o Rotary era acima de tudo uma associação privada de solidariedade interprofissional. Seu objetivo era facilitar os intercâmbios econômicos entre os membros das profissões liberais. Outros Rotary logo foram criados nas grandes cidades dos Estados Unidos, depois na Europa (1911) e no mundo. O Rotary experimentou um forte crescimento e se tornou uma rede de clubes que gradualmente se encarregaram da organização das atividades filantrópicas. Uma Fundação foi criada em 1917 para coordenar a atividade dos clubes em todo o mundo a partir de sua sede em Evanston, Illinois. O Rotary se implantou no Quênia em 1930 em Nairobi. Até a independência em 1963, a colônia contou apenas com três clubes. Foi apenas na década de 1980 que se multiplicaram neste país da África Oriental que conta hoje 40, incluindo 14 na capital.

Esta cronologia faz sentido quando apontamos para um contexto social e político mais amplo. 0 surgimento dos Rotary Clubs no Quênia está de fato correlacionado com a implementação dos programas de "ajuste estrutural" que levaram a profundas transformações políticas. De início, no âmbito do Estado, a condicionalidade da ajuda ao desenvolvimento favoreceu o prazo da liberalização econômica e política. Em seguida, no seio das elites, entre os segmentos excluídos do poder estatal pelo regime autoritário e nepótico de Kalenjin Daniel arap Moi (1978-2002). Estes se apropriaram do discurso da reforma e da luta contra a corrupção promovida pelas organizações internacionais para legitimar sua oposição ao governo e federar os apoios. Este é o caso especialmente da elite Kikuyu resultante da independência e do regime de Kenyatta (1964-1978), que foi particularmente prejudicada pela camarilha de Kalenjin à frente do estado. A moralização da vida pública, promovida pelos doadores, nutriu assim um "jogo simbólico de importaçãoexportação", graças ao qual a elite dos adversários do regime conseguiu forjar uma nova legitimidade no campo político local, garantindo a intermediação de padrões internacionais.

Esse fenômeno se espalhou para o campo econômico. Foi notadamente usado pelos chamados profissionais do Quênia, isto é, as profissões liberais reconhecidas pela lei e dotadas de corpos autorregulados: advogados, médicos, contadores, arquitetos, engenheiros. Não pode se livrar da predação e da arbitrariedade do regime com tanta facilidade os atores da economia informal, pois este grupo retomou os mantras da "boa governança" para alimentar a crítica política de um regime do qual ele foi excluído. Mais amplamente, essa crítica foi apoiada por um setor privado em formação, que as liberalizações ajudaram a estruturar. Os serviços cresceram fortemente, um número crescente de pessoas conseguiu enriquecer sem acesso direto ao Estado, reivindicando, portanto, uma acumulação

\footnotetext{
${ }^{4}$ Para uma análise detalhada do crescimento do Rotary nos Estados Unidos e na França, ver GOUSSET, Sandrine. "Sociabilidades burguesas e investimentos "filantrópicos": uma abordagem dos Rotary Clubs". Tese de doutorado em Ciência Política, Universidade de La Rochelle, 2004.
} 
independente de patrocínio político ${ }^{5}$. Ao mesmo tempo, a figura tradicional dos Grandes Homens, esses políticos empreendedores, especialistas em acumulação multiforme, que, na indiferenciação do público e do privado, organizaram suas redes clientelistas, foi desvalorizada. O uso tático da violência étnica nas primeiras eleições multipartidárias da década de 1990 só agravou o descrédito que os atingiu. São nessas circunstâncias que os profissionais e a comunidade empresarial conseguiram formar o quadro da coalizão partidária que assumiu o poder em 2002 em torno de Mwai Kibaki, representante de um programa resolutamente liberal ${ }^{6}$.

Até agora, essas mudanças eram principalmente consideradas como estratégias de atores no campo político ${ }^{7}$. A abordagem é parcialmente convincente, porque o compromisso com um Rotary pode realmente ser explicado pela posição que seus membros ocupam no campo de elite. Por tudo isso, porque que se adere à única arena política e ao que se relaciona explicitamente com ela, esta análise somente consegue capturar a dimensão internacional dos atores como uma tática cujos efeitos só podem ser medidos em termos de acesso formal ao Estado. Eu gostaria de ir mais longe aqui. De fato, a intimidade da sociabilidade da elite dá a ver, o mais próximo possível, a tradução da vida cotidiana do "jogo simbólico de importação-exportação", através do qual se legitima um segmento da classe dominante ${ }^{8}$. Seu estudo permite mostrar que o compromisso do rotariano não é apenas uma tática; também é, muitas vezes, uma disposição ética, um gosto; serve o imaginário de uma existência individual realizada. Nós podemos mostrar que as linhas divisórias da elite queniana não são apenas étnicas ou partidárias, porque marcam oposições de estilos, no sentido weberiano do termo. No final, o entre-si rotariano esclarece sobre o modo como as aspirações individuais para o sucesso econômico, ao reconhecimento social e a autoestima se misturam com a promoção para o Quênia dos mantras da "boa governança" e das liberalizações. Isso se segue a um relatório paradoxal de rotarianos ao Estado, evitando a concorrência política e seus excessos, mas também o mimetismo de suas práticas de legitimação: a burocracia, a tributação e através da filantropia, do serviço público.

\section{A sociabilidade de uma geração de elite}

\footnotetext{
${ }^{5}$ HANDLEY, Antoinette. "Variedades dos capitalistas? A classe média, o setor privado e os resultados econômicos na África". In: Journal of International Development, 27, 2014, p. 609-627.

${ }^{6}$ ARRIOLA, Leonardo R. Coalizões multi-étnicas na África: financiamento de negócios das campanhas eleitorais da oposição. Cambridge: Cambridge University Press, 2013.

${ }^{7}$ WORNG, Michela. Nossa vez de comer. London: Harper, 2010.

8 COEURDRAY, Murielle. "O duplo jogo simbólico de importação-exportação. A construção internacional de um novo discurso sobre corrupção". In: Proceedings of Social Science Research, 151-152, 2004, p. 80-90
} 
No espaço da sociabilidade da elite no Quênia, o Rotary é apenas uma instituição entre outras. Existem outros clubes - sociais, esportivos - que reúnem em grande parte as elites econômicas e políticas, em Nairobi, como nas grandes cidades da província. Embora suas listas de membros aderentes sobreponham parcialmente aquelas das instituições, os Rotary Clubs se distinguem pelo tamanho e tipo de sociabilidade que florescem lá. Eles reúnem dezenas de membros, contra várias centenas dos outros clubes, sua sociabilidade é limitada no tempo - algumas horas uma vez por semana - e responde a uma agenda. Em seu conjunto, o espaço de sociabilidade de elite em Nairobi é diferenciado e hierarquizado de acordo com determinantes estatutários, econômicos e raciais. Os Rotary Clubs são diferenciados primeiro pela sua antiguidade, que na maioria das vezes é de fato a dos seus membros. Assim, os Rotary Clubs são antes de tudo um negócio de gerações. Nairobi Central é um clube sexagenário; Nairobi Norte, Utumishi, Hurlingham, Nairobi Leste são frequentados principalmente por pessoas na casa dos cinquenta; Parklands e Muthaiga sobretudo pelos quarentões. Os clubes também são diferentes pela sua identidade racial, essa distinção é, além disso, sempre implícita. Existem clubes com uma maioria europeia (especialmente em Nairobi Central) ou mais geralmente com muitos expatriados (como Muthaiga ou Karen, os bairros sofisticados de Nairobi). Outros são exclusivamente indígenas, como na Área Industrial. Muitas vezes, a cor de um clube é aquela da área residencial ou dos negócios em que se encontra. Por outro lado, qualquer que seja o clube, os rotarianos são em grande maioria de executivos de empresas, homens e mulheres de negócios, e representantes das profissões liberais.

A este respeito, o Rotary Club de Langata tem duas propriedades notáveis: seus membros são jovens e quase todos africanos, como aqueles de outros clubes fundados no início dos anos 2000. Quando da sua criação, a média de idade dos membros fundadores do Langata era pouco mais de 30 anos. De fato, o Rotary de Langata foi lançado por membros do Nairobi Norte que incentivaram seus filhos a participarem do novo clube: encontramos aqui, além de Edward e seu primo Alex Nyaga, Mercy Mutua, a filha de um alto funcionário, secretária permanente da administração de Kibaki; Nancy, filha do grande chefe Peter Kanyago e June, filha de James Gachui, o fundador da Transcentury, a holding mais bem sucedida da África Oriental, especializada em infraestruturas.

Muitos dos rotarianos de Langata são, portanto, os herdeiros diretos de uma geração ferida de empresários e profissionais, especialmente kikuyu, traumatizados pelos anos Moi ${ }^{9}$ e pela presidência de Kibaki (2002-2013) que permitiu o retorno aos negócios. No entanto, essa filiação não é exclusiva, pois também encontramos filhos de aliados íntimos do antigo regime, por exemplo, o advogado Mutula Kilonzo Junior, filho do advogado Mutula Kilonzo, membro proeminente do Rotary Club de Nairobi Norte que supervisionou certas transações comerciais do Presidente Moi. A reunião no seio do Rotary das elites do antigo e do novo regime é contraditória apenas na aparência: o Rotary não é nem um clube da oposição

\footnotetext{
${ }^{9}$ Nota da tradutora: referência aos 24 anos de administração de Kalenjin Daniel Arap Moi, de 1978 a 2002 , quando foi substituído pelo presidente eleito Mwai Kibaki.
} 
nem o partido de uma faç̧ão política. O que reflete, por outro lado, através do exemplo de Kilonzo, é a estruturação, a partir da década de 1990, do campo das profissões liberais, aquelas que tinham sido fortemente afetadas pela crise econômica que elas se colocadas no setor informal e estavam na verdade, mais subjugadas que as outras ao jugo do estado ${ }^{10}$. Várias associações de profissionais, como a Sociedade de Direito do Quênia, tornam-se fóruns de oposição. Se elas usavam a linguagem da democratização, da liberalização e dos direitos humanos para se fazer ouvir e receber apoio, suas reivindicações eram para o reconhecimento de suas profissões, das habilidades tecnocráticas que possuíam, das suas formas de trabalhar e de um tipo particular de dignidade profissional em relação a um Estado cujo funcionamento era então julgado cada vez mais como arbitrário. A partir de então, o Rotary, em Langata como em outro lugar do Quênia, era o local de uma síntese entre empresas e profissões que, independentemente de suas lealdades partidárias, têm em comum as representações e interesse de se federar.

No clube de Langata, há certamente disparidades de riqueza e status entre as diferentes famílias das quais os rotarianos são originários, mas todos se beneficiaram de um ambiente social que lhes garantiu o acesso ao ensino secundário e superior. A maioria dos membros cresceu nos bairros ricos da capital, frequentaram as mesmas escolas e as mesmas universidades onde estudaram mais ou menos as mesmas coisas, Direito ou Administração. Além disso, numerosas são as amizades mantidas no clube que existiam bem antes da adesão: camaradagem escolar ou universitária, passagem da pupilagem ${ }^{11}$ nos mesmos grandes escritórios de advocacia, adesão as mesmas associações profissionais, frequentam as mesmas igrejas evangélicas. Muitos também possuem perfis internacionalizados quando se trata de uma característica familiar, acadêmica ou profissional. Alguns se encontravam no exterior, como June Gachui e Janet Onyang'o, quando o pai da primeira dirigia a filial da TOTAL em Abidjan, enquanto o pai da segunda presidia o Banco da África. Em muitos aspectos, a adesão ao clube também é uma confirmação, que conforta cada um em seu status, herdados ou adquiridos ${ }^{12}$. Além disso, por causa desses traços comuns, as histórias das primeiras vezes no clube são muito semelhantes. São várias pequenas epifanias onde os filhos das classes dominantes descobrem que eles já se conheciam.

A temporalidade da sociabilidade rotariana é intensa. As reuniões de Langata acontecem uma vez por semana, na quinta-feira às 19 horas, e se estendem informalmente até tarde da noite para terminar em

10 MAUPEU, Hervé e LAFARGUE, Jérôme. "Sociedade Civil Queniana: entre resiliência e resistência". In: Politique africaine, 70, 1998, p. 62-65. Esta análise baseia-se, em particular, nos dados registrados por Robert Bates, "A política da crise alimentar no Quênia ", em Michael Schatzberg (org). A economia política do Quênia. New York: Praeger, 1987, p. 75-92. Sobre a resistência do Estado de Direito do Quênia no regime Moi, consultar Stanley D. Ross, "O Estado de direito e os advogados no Quênia". In: The Journal of Modern African Studies, 30 (3), 1992, p. 421-442 e Paul Mwangi, As barras pretas: corrupção e intriga política na Fraternidade Legal do Quênia. Nairobi: Oakland Media Serviços, 2001, p. 104-116.

11 Para os juristas do mundo de língua inglesa, a pupilagem é a fase de aprendizagem em um escritório de advocacia que conclui qualquer formação inicial.

12 Refiro-me aqui à noção de Bewährung [provação] de Max Weber, que se sobrepõe a essa ideia. Veja especialmente detalhes lexicais de Jean-Pierre Grossein em Max Weber, A Ética Protestante e Espírito do Capitalismo. Paris: Gallimard, 2003, p. LIX. 
embriaguez. Elas são acompanhadas de eventos cuja frequência é menos regular, mas que permitem renovar relações entre os rotarianos: festas ou refeições privadas, visitas a projetos, levantamento de fundos em jantares ou torneios de golfe. Finalmente, entre duas reuniões, a sociabilidade rotariana também está se espalhando sobre as redes sociais, via Facebook ou Twitter, por exemplo, para a seleção de conferencistas, a redação de jogos e Quiz, a organização de projetos e de visitas. No Rotary de Langata, ninguém permanece anônimo: é um lugar onde as pessoas se empenham pessoalmente, e se parabenizam mutualmente. Mesmo os membros mais discretos são incentivados e felicita-se voluntariamente o jovem que tenha se sentido seguro e se expressar em público sem medo.

Aqui as relações amistosas são comparáveis às estabelecidas na universidade ou na igreja, mas neste caso é justificada pela prática profissional que determina a classificação do membro, como comprovado pelo crachá que cada um usa nas reuniões. O ritual rotariano também coloca os membros do clube num sistema de obrigações recíprocas, tanto morais (os idosos têm o dever de orientar os mais jovens) quanto materiais (os membros se devem apoiar e se dar assistência mútua). Nas reuniões, cada pedido de pratos e de bebidas não é só para si, mas também para os seus vizinhos de mesa; os rotarianos contribuem coletivamente para os custos do funeral dos pais de seus membros; para os custos de hospitalização dos seus doentes, incluindo membros próximos da família. No clube, essa solidariedade horizontal também é manifestada por cartões de aniversário que circulam ao longo das duas grandes mesas da sala reunião e em que todos escrevem uma palavra; a comemoração, no início de todos os meses, dos aniversariantes do mês, são celebradas com canções e com um grande bolo; assim como o anúncio público de um nascimento ou de um casamento. Através de gestos, trocas ou doações, que muitas vezes parecem insignificantes, os rotarianos do mesmo clube estão constantemente ligados pela circulação de uma dívida implícita que faz cada um ter dever com o outro. Eles contribuem para alcançar a solidariedade de classe fundada sobre uma relação de confiança e de favor.

Os momentos mais informais que se seguem à sessão "oficial", que dura aproximadamente uma hora, ou duas no máximo, são particularmente importantes. Apelidado de swallowship - do verbo engolir (swallow) e companheirismo (fellowship) - pelos rotarianos de Langata, eles misturam injunções com companheirismo que são próprios para qualquer clube e uma alcoolização significativa. Estendem a reunião até muito tarde da noite, muitas vezes até uma ou duas da manhã, e em paralelo com compromissos profissionais, constituem uma "comunidade de lazer" soldada pela libertação dos afetos que a bebida permite ${ }^{13}$. Agora, se definitivamente se bebe muito - um bar está instalado nos fundos da sala de conferências com três garçons em atividade - também se discute negócios, comenta-se a situação do

\footnotetext{
${ }^{13}$ Norbert Elias fala a respeito da "vara comum de laser" ou "comunidade emocional", e insiste, em particular, no papel do álcool na liberação dos afetos, em um nível muito maior do que é normalmente tolerado no exercício normal das funções profissionais e, mais amplamente, de não lazer. ELIAS, Norbert e DUNNING, Eric. Esporte e civilização: a violência controlada. Paris: Fayard, 1994 (1986), p. 165-169.
} 
mercado, do setor econômico, apresenta-se projetos. Os rotarianos se seguem, por assim dizer, em todos os lugares: sempre que um deles organiza um evento extraprofissional - Muchau Githiakia, capitão do Vet Lab Golf Club, um torneio de golfe; June Gachui, um concerto de jazz -, um grupo de rotarianos, que muitas vezes representa pelo menos um terço dos membros do clube, vem e forma um público solidario, mas não se mistura com os outros convidados.

A participação em um Rotary permite que seus membros estabeleçam entre si um esquema de preferência que tem consequências em termos de parceria comercial ou investimento. Muitos rotarianos de Langata formam no seio do clube grupos de investimento. Trata-se de acumular fundos em uma sociedade com fins especulativos, na maioria das vezes em propriedades urbanas. Estas ligações também têm repercussões em termos de emprego. Por outro lado, a solidariedade rotariana não substitui sistematicamente os laços que unem os membros da mesma família ou igreja ${ }^{14}$.

\section{O profissional como tipo de homem}

O Rotary promove implicitamente um modelo de "homem realizado", uma "figura de sucesso"15 cujos contornos são traçados de acordo com as reuniões. Então, cada semana, os membros do clube convidam um palestrante, que faz uma exposição com cerca de vinte minutos. Os temas tratados nessas intervenções desenham um estilo de vida desejável, aquele do profissional, homem de negócios próspero, o empresário bem-sucedido, o executivo da empresa performática. Eles tratam em geral, de um aspecto em que a auto melhoria de si é considerada possível, seja no campo pessoal, familiar ou profissional. São abordados, por exemplo, através de uma apresentação de power point o que parece imperativo, a tomada da palavra em público, por um treinador profissional que conta, entre outros, entre a sua clientela com vários grandes líderes empresariais e membros do parlamento ${ }^{16}$. Ross Van Horn, um consultor americano de gerenciamento estabelecido em Nairobi, trata, da maneira de como "desenvolver e usar suas redes para o seu sucesso pessoal e profissional". Ele encoraja o público a classificar suas relações sociais em várias categorias, dependendo do seu papel e da sua utilidade, desde os "modelos" dos "concorrentes" passando pelos "amigos íntimos", pelos "ajudantes" ou ainda pelos "interesses comuns", categorias que, combinadas, formam um "sistema de suporte pessoal". Trata-se de escolher as pessoas certas conforme as necessidades, respeitando quatro princípios no uso desses contatos: "equidade, parcimônia, manutenção,

\footnotetext{
${ }^{14}$ Ao contrário da classe média melanesiana, que se definiria em primeiro lugar pela capacidade de se extrair das dependências do patrocínio rural. ERRINGTON, Frederick e GEWERTZ, Deborah. "O Rotary Club de Wewak: a classe média na Melanésia". In: The Journal of the Royal Anthropological Institute, 3, 1997, p. 333-353.

${ }^{15}$ BANEGAS, Richard e WARNIE, Jean-Pierre. "Novas figuras do sucesso e do poder". In: Politique africaine, 82 (2), 2001, p. 5-23.

${ }^{16}$ Notas de campo, 4 de junho de 2009.
} 
retorno". No exemplo dado, era para escolher as pessoas certas para obter "um MBA de uma instituição respeitável antes de junho de 2014" ou para ter sucesso em sua reconversão profissional. Durante a apresentação, o treinador distribuiu cartas para ajudar os participantes a classificarem suas relações: em linhas, os tipos de relação, em colunas, o tipo de ação a considerar. Cada um exercitou sua triagem. 0 treinador também transmitiu na tela um gráfico sob a forma circular, onde estavam proporcionalmente representados os diferentes tipos de relacionamentos que ele próprio mantinha. A sala aplaudiu e levantou perguntas: "Esse sistema pode ser aplicado a uma empresa?"; "Como medir com indicadores precisos o valor do seu sistema de suporte?"; "Podemos dar-Ihe uma nota, um número?"17.

Outra apresentação centrava-se na promoção de um evento organizado pela Training Solutions Ltd., uma filial queniana do escritório de consultoria KPMG, que convidou para ir ao Quênia os gurus internacionais da gestão e do desenvolvimento pessoal quando do Guru Events: Robin Sharma, autor do best-seller 'O monge que vendeu sua Ferrari', ou ainda o "profeta dos negócios" C. K. Prahalad, autor de 'A fortuna no fundo da pirâmide ${ }^{18}$. Um outro desses eventos foi na forma de um seminário intitulado "Os hábitos de liderança dos Campeões Empresariais da África Oriental", onde foram convidados 14 dos maiores líderes e empresários quenianos, e por videoconferência um dos gurus da administração americana, Gary Hamel. Ao longo do dia, essas personalidades prestaram assistência a uma audiência reduzida. A apresentação foi seguida de um treinamento personalizado. Na reunião do clube onde o evento foi apresentado um ingresso - normalmente vendido a 65000 xelins do Quênia (KSh) (650 euros) - é dado ao clube para ser leiloado: os rotarianos decidem que aquele entre eles que ganhar o leilão será obrigado a fazer uma resenha do evento para os outros ${ }^{19}$.

Outra exposição apresentou Lemmy Maloiy, que administra uma empresa de consultoria independente sob uma franquia internacional chamada Action Business Coach. Lemmy veio falar no Rotary sobre uma iniciativa que ele lançou: um Clube de Lucros, um grupo de cerca de vinte empresários que se reúnem duas vezes por mês em um restaurante de Nairobi para compartilhar seus conhecimentos e experiências. O nome do clube é sem ambiguidade: "Você ganhará mais lucros. Você estabelecerá conexões fortes com pessoas que se parecem com você, em um ambiente projetado para melhorar sua empresa".

Serviços bancários, seguros e mercado imobiliário são tópicos recorrentes, como por exemplo o crédito agrícola com Housing Finance, ou o serviço bancário prioritário do Banco Barclays, o projeto Thika Greens, cujo um dos promotores é um membro do clube.

\footnotetext{
17 Notas de campo, 12 de agosto de 2010.

18 Notas de campo, 6 de agosto de 2009.

${ }^{19}$ Notas de campo, 23 de outubro de 2008.
} 
Na repetição desses discursos, notamos uma transformação das relações com a terra, vista como uma fonte de auto realização para os rotarianos. Um dos membros explica os motivos que o levaram a desenvolver, $40 \mathrm{~km}$ a leste de Nairobi, o centro de "agroturismo" de Gramonra Gardens, do qual ele é o CEO e onde ele propõe alugar aos "urbanitas rurais" da capital um pequeno lote de terra para cultivar. 0 objetivo é redescobrir os encantos da vida rural para as pessoas urbanas que deixaram há muito tempo o campo $^{20}$. Em cada terreno, a empresa cuida de todos os aspectos técnicos da cultura de alto retorno: tomate, batata, melancia, feijão; uma lagoa de peixes também é fornecida para a pesca. Os executivos de Nairobi podem chegar lá quando quiserem. Eles encontraram em cada uma de suas visitas os agricultores que estão no local permanentemente e os ajudam nos aspectos mais agradáveis da manutenção de suas colheitas, por um aluguel e por uma taxa sobre os produtos cultivados que são revertidos em benefício de Gramonra Gardens.

Este gosto por terras recreativas está muito presente nos rotarianos que raramente investem em uma fazenda que eles dificilmente teriam tempo para cuidar, enquanto outros investimentos mais lucrativos Ihe estão disponíveis. Sailapu Montet comprou assim um lote de terra em Karen, próximo das colinas de Ngong, onde ele fez uma piscina e um pequeno rio artificial, plantou arbustos e flores, instalou pedras e uma fonte, bem como um terraço coberto e uma churrasqueira; um castelo inflável e amplo estacionamento completam o pacote. No Natare Gardens, você pode organizar refeições familiares, aniversários, seminários para formação de equipes corporativas, organizar um nyama choma (churrasco com várias carnes grelhadas) com os amigos. Ao organizar neste local os Dias da Família Rotariana (jornadas destinadas às famílias) durante os quais há cursos voltados para as crianças, carne de cabra grelhada e pequenos jogos de futebol, o Rotary Club de Langata reforça a ideia de uso de uma terra antes sem utilidade e, doravante dedicada ao lazer e aos jogos.

Outra noite, os doutores Dan e Betty Gikonyo promoveram o Karen Hospital do qual são os fundadores. Os dois cardiologistas - Dan é o médico pessoal do presidente Mwai Kibaki - retraçaram o longo percurso, desde o doutorado em Minneapolis até a construção em 2006 desta clínica de 100 leitos, que tornou os dois as figuras mais respeitadas em Karen, onde são membros do Rotary Club. Concluem sua apresentação dedicando algumas palavras a Fundação Heart to Heart, uma associação de caridade e saúde para crianças desfavorecidas ${ }^{21}$.

No Rotary, a recepção desses discursos é um pouco crítica. Na maioria das vezes, os participantes aplaudem o orador, solicitam uma cópia eletrônica do texto de sua intervenção e tendem com suas perguntas a apoiar sua visão das coisas.

\footnotetext{
20 Notas de campo, 22 de julho de 2009.

${ }^{21}$ Notas de campo, 2 de dezembro de 2010.
} 
O modelo do homem consumado e da vida ideal que é construída ao longo das reuniões, apresentações e conversas informais que acompanham ou animam o encontro não é apenas sobre a atividade econômica: também abordam a luta contra o câncer, diabetes e o restaurante "Bio" Bridges explica aos rotarianos quais são os fundamentos de uma dieta saudável e equilibrada. Ao associar essas recomendações sanitárias à promoção de certos esportes - várias vezes por ano, o clube organiza levantamentos de fundos sob a forma de torneios de golfe - o clube é uma instituição que regula as condutas e as complexões corporais, e tende a otimizar as capacidades dos seus membros ${ }^{22}$.

Não existe melhor exemplo do que o de Eric Kimani para representar, no espírito desses discursos, o rotariano realizado. Eric Kimani é membro do Rotary Club de Nairobi Norte e desempenhou um papel ativo na criação do Rotary Club de Langata. Aos 52 anos, ele foi de 2011-2012 Governador de Distrito do Rotary, isto é, ele foi o representante eleito de todos os Rotary Clubs da África Oriental. Ele foi o primeiro africano queniano a ocupar esse cargo. Depois de ter exercido responsabilidades financeiras no setor do chá e do café e ter assumido a direção da Agência de Desenvolvimento do Chá do Quênia, ele é desde 2005 o CEO da Sameer África, franquia do leste africano fabricante dos pneus Firestone. Administrador de um site na internet com seu nome (www.erickimani.org), Kimani declara que um dos seus objetivos é "fazer de mim mesmo uma marca" em tudo o que ele administra. Ele se apresenta como um "líder em negócios, um motivador e um filantropo".

Kimani é antes de tudo um empreendedor realizado. Além de suas funções como CEO da Sameer, ocupa cargos de direção em várias empresas, principalmente no setor bancário e financeiro. Ele também é o fundador das Leiterias de Palmhouse fornecendo produtos frescos aos hotéis mais prestigiados da capital queniana, uma filial privada da Faculdade de Contabilidade do Quênia, bem como uma escola primária privada.

No entanto, o sucesso econômico não é suficiente para o reconhecimento e Kimani, que cita em sua página na internet Napoleon Hill, também se apresenta como um benfeitor e filantropo: "Aqueles que trabalham apenas por dinheiro, e que recebem como salário de seus esforços somente dinheiro, estão sempre mal pagos, independentemente do valor que recebem. O dinheiro é, naturalmente, necessário, mas as recompensas reais que se pode esperar de uma existência não pode ser medidas em dólares e cêntimos". Como mentor, ele recebe os rotarianos em casa para sessões de coaching, tem uma plataforma com várias revistas de gestão e participa de vários seminários para compartilhar sua experiência, e especialmente para pregar sua "filosofia", a "Perspectiva da Abundância": "A crença de que um pensamento prolífico é a chave para revelar nosso potencial enquanto seres humanos. Um pensamento prolífico é definitivamente poderoso, pode nos permitir tomar as nossas vidas em nossas mãos. Leia e pense muito!" Como filantropo, ele criou uma fundação educacional que fornece bolsas de estudo para o

\footnotetext{
22 FASSIN, Didier e MEMMI, Dominique. O governo da vida, instruções de uso. Paris: Edições do EHESS, 2004, p. 9-24.
} 
ensino secundário e preside a filial queniana da ONG britânica Helpage International. É finalmente um jogador de golfe realizado. Governador do Rotary, ele decidiu, reunir os membros dos seis clubes criados pelo Nairobi Norte ${ }^{23}$, o qual contava somente com uns vinte membros ativos ${ }^{24}$. Ele apelidou esse grupo de 'Os Sete Magníficos' e os reunia a cada três meses para um nyama choma em sua propriedade de Ruiru, que ele batizou de 'A toca dos apaixonados'. É um grande pedaço de terra adjacente à rodovia seis pistas de Thika, onde ele cria cavalos à beira de um lago artificial iluminado por luzes de néon. Eric Kimani encarna esse discurso difuso cujo Rotary é apenas um teatro, cuja principal característica é sem dúvida transferir ao indivíduo a responsabilidade pelo seu sucesso econômico e social.

Então, o estilo de vida do gerente não é uma consequência ou um subproduto de sua técnica de trabalho e acumulação, ele forma um todo. A associação ao clube, as formas de ser promovido ali, é completamente constitutivo da posição de classe dos rotarianos.

\section{A forma de um evangelismo antipolítico}

Basicamente, a ética rotariana liga a sensação de trabalhar para o bem-estar coletivo e a busca do interesse individual. Como Moses Muriithi explica: "O Rotary, para mim, é uma questão de doação social e desenvolvimento pessoal. Você progride internamente ajudando os outros ao seu redor"25. É por esta razão que a filantropia desempenha no Rotary um papel central. Ela responde de qualquer maneira ao princípio da "obrigação de nobreza" que implica justificar pela doação sua posição social privilegiada. Esta doação é feita de várias maneiras, mas não é direta, pelo menos quando é feito em público, e se encaixa em uma série de realizações que tendem a fazer a transferência de dinheiro menos óbvia. Na maioria das vezes, é feito no modo de jogo, da competição amigável entre membros ou entre mesas, pelo leilão dos bens oferecidos pelos membros ou empresas (na maioria das vezes garrafas de vinho ou whisky que em seguida eles bebem juntos), ou por loteria cuja receita dos bilhetes financia o clube e seus projetos. Isto é, de acordo com as palavras do presidente George Masese, de "dar sem aparecer".

No entanto, aqueles que dão mais do que outros no espaço do clube não passam despercebidos. 0 rotariano queniano primeiro dá porque ele pode, e para demonstrar, para mostrar a si mesmo, que ele o pode, tanto dentro como fora do clube. A doação também se encaixa numa lógica de distinção e os rituais que a acompanham em Langata são a ocasião de uma competição mundana entre seus membros mais

\footnotetext{
${ }^{23}$ Karura, Karen, East Nairobi, Thika, Langata e Nairobi Mashariki.

24 O Rotary Clube do Nairobi Norte foi, no passado, muito mais bem-sucedido, reunindo personalidades de primeiro plano como Mutula Kilonzo, James Gachui e Peter Kanyago, bem como os juristas Paul Ndung'u e Sharad Rao ou Musembi Mbathi, exSecretário Permanente de Administração Moi, Irmão de Titus, Ministro e presidente da empresa de energia KenGen.

${ }^{25}$ Entrevista com Moses Muriithi, Nairobi Club, 6 de agosto de 2009.
} 
ricos. No entanto, a doação rotariana entra em conflito com as obrigações sociais percebidas no restante da sociedade queniana: doação de projetos, como geralmente é praticada sob a forma do harambee (literalmente "vamos atirar juntos"), tontina pública organizada pela administração para financiar projetos de desenvolvimento, é de início uma maneira dos políticos manterem uma clientela e é entendida como tal. Alguns anos atrás, quando ele lançou o projeto para refazer o telhado de uma escola em sua região natal, o rotariano Wafula Nabutola recebeu uma ligação telefônica do deputado da circunscrição que Ihe pediu para declarar suas ambições políticas ${ }^{26}$. Inversamente, a doação rotariana é uma forma de se livrar das obrigações financeiras relacionadas à família estendida, da aldeia, da região, da "dívida comunitária infinita"27. Quando Moses Muriithi diz que, na sua aposentadoria, ele dará metade do seu benefício ao Rotary, é também para escapar da dispendiosa relação clientelista que o une a vila de onde ele veio e a qual seu pai era obrigado a seguir: "Entre as coisas que mataram meu pai, há todos aqueles harambees que ele estava fazendo quando ele estava aposentado. Ele distribuiu muito dinheiro através de todos os seus amigos. Mas com o Rotary fazemos mais que levantar fundos, no Rotary a doação é sistemática. Como tal, há um acompanhamento, seja qual for a arrecadação de fundos"28.

Ainda assim, a doação dos rotarianos quenianos não é apenas monetária, que na realidade é muito pouco. A reunião de Langata resulta no levantamento de 10.000 a 20.000 KSh (100 a 200 euros) para 40 a 50 membros presentes em média, isso representa entre 250 e 400 KSh (2,50 e 4 euros) por pessoa, contados por um membro eleito do clube com o título de Sargento das Armas. Certamente um rotariano pode doar diretamente à Fundação, mas essas doações também são todas bastante limitadas. Por exemplo, os rotarianos que contribuíram de uma vez com 1.000 dólares para a realização de um projeto recebem o status e o distintivo de Companheiro Paul Harris. Este distintivo dá-Ihes um reconhecimento especial dentro do clube, bem como as honras do jantar que reúne todos os anos todos os clubes. Logo é na ocasião de tais eventos que vemos o quanto os doadores rotarianos são poucos numerosos e, no Quênia, são principalmente indígenas ${ }^{29}$. Com cerca de 70 membros, o Langata tem menos de 10 distintivos Companheiro Paul Harris, que são principalmente de seus membros mais velhos. É muito pouco em comparação com a maioria dos Rotary Clubes asiáticos.

\footnotetext{
${ }^{26}$ Entrevista com Wafula Nabutola, Parklands Sports Club, 15 de outubro de 2008.

27 MARIE, Alain. "Avatares da dívida comunitária: crises de solidariedades, bruxaria e processos de individualização (itinerários de Abidjan)". In: MARIE, Alain (org). África dos indivíduos: itinerários citadinos na África contemporânea (Abidjan, Bamako, Dakar, Niamey). Paris: Karthala, 1997, p. 249-328.

${ }^{28}$ Entrevista com Moses Muriithi, citado.

${ }^{29}$ Por outro lado, esses indígenas dão muito, uma vez que um deles, considerado como o maior doador queniano, doou à Fundação mais de meio milhão de euros em sua carreira rotariana. Por outro lado, neste jantar, onde são chamados os maiores doadores, podemos ver que quase todos os membros do Rotary Club de Nairobi da Área Industrial, um clube indígena, são Companheiros Paul Harris. Notas de campo, 18 de novembro de 2010.
} 
É que a doação rotariana é acima de tudo, para os profissionais, uma doação de habilidades. Provém de uma racionalidade gerencial, onde a eficiência do investimento é principalmente uma questão de padrões, procedimentos, contratos, desempenho. Ele não é discriminatório, e se inscreve em contraste e em competição com a doação clientelista dos políticos. É por esta razão que Kimani, quando ele era Governador do Rotary para a África Oriental, defendeu a ideia de que a filantropia deveria dar origem a isenções fiscais, uma vez que as fundações estavam envolvidas na construção nacional. Ele convidou o setor privado para trabalhar pelo bem público através da filantropia, não só para demonstrar a boa vontade dos empresários quenianos, mas também para legitimar suas intervenções em parcerias públicoprivado $^{30}$.

Na verdade, cada Rotary se apresenta como um serviço de clube. A caridade, o financiamento e a implementação de projetos de desenvolvimento são essenciais. No contexto queniano, isso significa que o Rotary está substituindo o Estado no que deveriam ser as suas obrigações para com os cidadãos. O serviço prestado pelo Rotary é uma crítica ao funcionamento do Estado. Para quem participa, ele opera e legitima uma reorientação das obrigações sociais e morais. Ele liga o bem coletivo para o enriquecimento individual, e através da prática de uma caridade que poderia dizer que cega e despolitiza os riscos da doação e contradiz os circuitos usuais do clientelismo político.

Quando perguntei a Ann Nabutola, ex-presidente do Rotary Club de Muthaiga, se os rotarianos dão importância à abertura de suas reuniões com um brinde ao presidente da República, ele respondeu: "Eu acho que é importante para nós reconhecermos isso como rotarianos que operam no Quênia, nós que oferecemos serviços que normalmente deveriam ser entregues pelo governo, uma vez que fazemos o trabalho do governo, então para nós, para que estejamos do mesmo lado, é bom reconhecer o Presidente deste país. É como, como você diz em inglês? Uma sátira! Eu o digo, se você quiser me vencer, não venha com um rungu (uma vara), (...) venha simplesmente com palavras, e não me fale com dureza, apenas me diga "Oh, você está indo bem", ou então você considera minha gestão está uma bagunça, você vem e varre, e talvez depois de um tempo, eu me direi ", mas por que ele está varrendo? Talvez eu deveria varrer antes que ele chegasse", esse tipo de coisa. Quando você pensa sobre isso, o Rotary não deveria fazer o que ele faz. Se o governo fizesse o que trabalho para o qual foi eleito, ele forneceria água, para todos, eletricidade, para todos, infra-estrutura, para que as pessoas possam plantar suas culturas e as crianças já não ficariam mais na rua. (...) Mas, de fato, o que dizemos ao governo, quando fazemos isso, é "o que você faz é ruim, você não faz o que você deveria fazer"131.

\footnotetext{
30 KIMANI, Eric."Faça filantropia para o próximo criando diretrizes impermeáveis". In: Business Daily, 15 de março de 2012.

${ }^{31}$ Entrevista com Ann Nabutola, G4S, Nairobi, 20 de agosto de 2010.
} 
É assim que devemos primeiro entender a natureza da caridade rotariana: ao assumir serviços que são prioritariamente de responsabilidade do Estado, o clube enfatiza as falhas e os erros dele e atua como um gabinete nas sombras do governo. Além disso, esta crítica é indireta, está enraizada em estratégias de prevenção desenvolvidas durante os anos difíceis do regime de Moi. No entanto, ao substituir o estado, mesmo em pequena escala de cada projeto - a construção de uma escola, de um sanitário ou de um dispensário em uma área deserdada, financiar os estudos do ensino médio e universitários de alunos e estudantes - a seção Ação e Programas de cada clube destaca as virtudes da razão administrativa do Rotary.

A dialética com o estado também existe em um nível formal. Parece que o funcionamento do Rotary reproduz de forma atenuada várias componentes do poder estatal: a tributação, com a coleta das doações; a coerção, com o estabelecimento de um aparelho disciplinar relativamente rigoroso; as eleições, com a nomeação do gabinete; o serviço público, com a organização de projetos, todos emoldurados do início ao fim de cada reunião, pelo canto do hino nacional e pelo brinde ao presidente da República. Finalmente, qualquer reunião do Rotary é um ritual sujeito a regras rígidas que o Sargento das Armas é o responsável por se fazer cumprir. A reunião começa em hora precisa e dura entre uma ou duas horas; todos os participantes devem ser nomeadamente identificados por um crachá, bem como seus possíveis convidados presentes na reunião; as rodadas de fala são definidas juntamente com o secretário antes do início da reunião e cada intervenção, se faz em pé, de frente para a plateia, e é introduzida pela fórmula consagrada "Senhor Presidente, Companheiros Rotarianos e Convidados". Os atrasos e conversas paralelas são punidos com multas, assim como as faltas cometidas na execução do ritual: hesitações na oração rotariana ${ }^{32}$ que abre cada encontro, ncapacidade de recitar em público o "teste das 4 vias"33 que deve orientar as ações dos membros. É essa capacidade de auto restrição para as regras disciplinares que fundamenta a autoridade moral do rotariano e faz Ann Nabutola dizer: "Se este país fosse governado como o Rotary, bem, eu acho que este país iria mais longe" ${ }^{14}$.

A crítica dos políticos, os profissionais do clientelismo político, é recorrente entre os rotarianos. Se um escândalo de corrupção explode, os rotarianos comemoram a expulsão dos políticos culpados. Quando o Ministro dos Negócios Estrangeiros, Moses Wetangula, e seu secretário permanente, Mwangi Thuita, foram suspensos como resultado de práticas abusivas que acompanharam a aquisição do local da embaixada do Quênia em Tóquio, Alex Nyaga, seguido por outros, anunciou publicamente que ele deu um "feliz 1.000" - ou seja, 1.000 KSh (10 euros) - ao clube para comemorar o acontecimento. Uma semana

\footnotetext{
32 Que tem diversas versões, a mais utilizada é "Ô Senhor, dispensador de todo bem, nós te agradecemos o pão nosso de cada dia. Que nossos amigos do Rotary e as regras do Rotary nos ajudem a Te servir todos dos dias. Amém".

33 "É conforme a VERDADE? / É LEAL de ambos os lados? / É suscetível de estimular a BOA VONTADE RECÍPROCA e de criar as MELHORES RELAÇÕES AMIGÁVEIS? / É BENÉFICO a todos os interessados?"

${ }^{34}$ Entrevista com Ann Nabutola, citada.
} 
antes, era o nome do ministro da Educação, William Ruto, que havia sido zombado após o anúncio do seu julgamento devido a um caso de corrupção relativo à venda ilegal de uma parcela da floresta pública ${ }^{35}$. Uma noite do ano de 2010, quando o primeiro-ministro Raila Odinga estava hospitalizado, um membro de Langata anunciou que desejava uma boa recuperação para o "baba" ("Papa", apelido em geral do político do qual se é o cliente). Outro membro então exclamou: "que baba? ", assim expressando sua recusa em reconhecer como figura tutelar o maior político luo ${ }^{36}$. Outra noite, quando a swallowship começou tardiamente, três profissionais da Província Central reunidos ao redor da mesa começaram a imitar seus respectivos deputados, ostensiva e grotescamente, alternando entre o gikuyu (linguagem vernácula dos Kikuyu) e o inglês, destacando o Honroso seguido pelo nome dos eleitos em questão, imitando suas promessas aos eleitores, suas meias palavras e sua má fé37.

Certamente, a preferência daquele que formula essas críticas vai para um campo diferente daquele que debocha. No entanto, são os políticos e suas práticas que são ridiculizadas, face ao governo presumido virtuoso dos empresários. Toda sua ética distingue os profissionais do mundo da política: sua gramática da doação, seu primado dado a competência como fonte de legitimidade, sua racionalidade gerencial, a manutenção de seu corpo e seu controle do tempo, inteiramente contidos no imperativo de manter o cronograma da reunião, quando a autoridade do político se dá pela ausência e pela espera.

Não se pode esquecer que o Rotary é também um círculo de negócios onde a reputação e a confiança recíproca são fundamentais. Essa é toda a importância de um clube fechado, de sociabilidade inscrito na duração, onde cada um é responsável por suas ações perante os outros. Os membros de Langata insistem no seu desejo de preservar a todo custo a reputação de "integridade" do clube, o que significa que cada passo falso de um deles envolve a reputação de todos os outros. A honestidade nos negócios e o respeito dos contratos, a credibilidade são princípios que as autoridades do clube pretendem defender. Um rotariano de Langata, chefe de uma agência de turismo, foi responsabilizado publicamente e expulso depois de ter vendido aos membros prestações não conforme ao orçamento ${ }^{38}$. É compreensível, atendendo a esses requisitos, que o político, como o veem esses profissionais, faça a figura do contra modelo.

A filantropia rotariana é, acima de tudo, um repertório de legitimação dos profissionais face aos abusos cometidos pelo pessoal da política. Não se trata de uma estratégia política, mas da afirmação moral de um grupo; é uma ética em vez de uma tática. Regularmente convidado para os eventos do Rotary, PLO Lumumba, o czar queniano da luta contra a corrupção e presidente da Comissão Anti-Corrupção do Quênia

\footnotetext{
35 Notas de campo, 28 de outubro de 2010.

36 Notas de campo, 1 de julho de 2010.

Nota da tradutora: Etnia Luo habita a região do Quênia, Tanzânia e Uganda.

37 Notas de campo, 7 de junho de 2010.

${ }^{38}$ Entrevista com June Gachui, Nairobi, 7 de dezembro de 2010.
} 
de 2010 a 2011, apela regularmente, em suas audiências para a libertação dos demônios do nepotismo e do tribalismo usando as palavras e o tom de um salmo. Em 21 de abril de 2011, ele foi convidado para fazer o discurso de abertura da conferência anual do distrito do Rotary em Kampala, que reuniu mais de 1.800 membros dos clubes da África Oriental. O tema da conferência foi "Construindo comunidades, ligando os continentes: o papel da boa governança". "Boa governança", nas palavras de Lumumba, deveriam se enraizar na vida cotidiana, até mesmo nas pequenas ações dos membros: "Enquanto eu estava sentado aqui, um amigo me enviou um SMS. Era uma mensagem da Bíblia muito antes do nascimento de Cristo. (...) Uma mensagem da história de dois indivíduos; um chamado David, vocês o conhecem, o outro chamado Golias, e vocês também o conhecem, graças à história. E ele me disse, neste SMS, que quando os israelitas foram lá e viram Golias, eles voltaram e disseram: "Ele é tão grande! Não podemos vencê-lo! " Quando David foi vê-lo, ele disse: "Ele é tão gordo, não posso perder! "[aplausos]. Mas você que está aqui, quando você olha para o mundo, os problemas são monumentais. Há almas sensíveis que dizem "ele é tão grande, por que tentar algo?" Mas eu sei que vocês rotarianos, quando vocês saem e veem os problemas vocês dizem: "É tão grande. Temos de desempenhar a nossa parte, porque se isto precisa ser feito, isso deve e será feito, porque se não o fizerem, nós o faremos! Obrigado e Deus te abençoe" ${ }^{139}$.

Os discursos de Lumumba capturam muitos aspectos da ética rotariana. Ela se alimenta de um sincretismo secular, que é tanto a chamada a união despolitizada de todos, e o sonho desta união de um futuro melhor para o país e para todos. Duas dimensões se misturam aqui, a política - ou mais precisamente, antipolítica - e a teleológica.

Antipolítica, em primeiro lugar, porque a ética rotariana é levada por um sonho de emancipação das contingências da vida política. Mais do que uma economia sem Estado, os profissionais quenianos sonham com um Estado sem políticos. Eles produzem, portanto, uma crítica específica do campo do poder, alimentada pela memória do Regime de Moi e pelas promessas não cumpridas da presidência de Kibaki. Os grandes casos de corrupção, mas também, e acima de tudo, as violências cometidas durante as eleições de 2007-2008, que causaram a morte de quase mil cidadãos quenianos e o deslocamento forçado de várias centenas de milhares deles, custou muito ao setor privado. As acusações caíram sobre os eleitos cujas práticas cllientelistas só podem prejudicar o desenvolvimento desse setor privado como o pilar do desenvolvimento do país. Isto é para substituir a imprevisibilidade da política eleitoral com um governo virtuoso de empreendedorismo, legitimado por doações que são em primeiro lugar doações de competência e que se opõem ao descuido dos eleitos. É nesse contexto que o registro religioso é reutilizado, como o que traz sonhos de prosperidade, de amor e unidade, de luta contra o mal e de superação do sofrimento e frustrações diárias. É através destas práticas que ocorre a ligação entre um nacionalismo que é, antes de mais, uma fantasia antipolitica de desenvolvimento e a prosperidade dos

39 PLO Lumumba, Discurso de abertura da 86a Conferência Anual do Distrito do Rotary em Kampala, Uganda, 21 de abril de 2011. 
destinos individuais ${ }^{40}$. Este é um registro ainda mais despolitizado do que os profissionais que o empregam são, pela sua função econômica mesmo, livre das relações de patronagem clientelista e das relações de produção ${ }^{41}$. Seu uso recreativo da terra, seu desejo de emancipar-se da servidão e das obrigações da aldeia testemunham isso.

Teleológica, então, porque o registro religioso concede em particular uma narrativa de desenvolvimento e modernização. Nesse sentido, a filantropia, bem como o imperativo de integridade que muitas vezes a acompanha, é primeiro uma relação com o futuro, a percepção do comportamento necessário para a realização de um Quênia considerado reputado. Os rotarianos se definem primeiro como os homens do amanhã. Quando fui convidado a apresentar brevemente minhas pesquisas no Rotary de Langata, um membro me perguntou se eu trabalhava sobre o crescimento das classes médias. Ele foi imediatamente contraditado por outro: "Nós pertencemos à classe alta (...), pelo menos é para isso que estamos apontando". A "cidade", a qual os empresários querem é a cidade do futuro, aquela que lhes promete, por exemplo, o plano Visão 2030, ao final do qual o Quênia se tornará, graças aos seus esforços, um "país de renda média", orgulhoso de seus trens de alta velocidade e de sua Savana Silicon, um espaço onde, enquanto indivíduos, eles poderão enfim se realizar ${ }^{42}$.

Em 2011, poucos dias antes do Natal, membros do Rotary Club de Langata reuniram-se para uma das últimas sessões do ano. Todos foram convocados para fazer uso da palavra sobre o assunto de sua escolha. Peter Warutere, do Banco Mundial, começou em seguida, uma apresentação sobre o tema "Onde estamos?", e desenvolveu o seu ponto de vista em torno do crescimento das infraestruturas, do novo porto de Lamu, do desvio de Nairobi, da rodovia de Thika. Nick Bore assumiu o comando, explicando o aumento do preço dos produtos petrolíferos, suas consequências para a inflação, a forma como ameaçou os projetos que Peter acabava de fazer o balanço. O debate tomou conta da sala. Cat Gachie falou sobre o crescimento de Nairobi, a necessidade de um trem ou um metrô para conectar os diferentes bairros. Todos contribuíram, os rotarianos juntos imaginando o Quênia do futuro ${ }^{43}$.

Finalmente, lembremos que a utilização do repertório religioso é um costume rotariano secular. Certamente, ele imprime sua forma nos discursos e nas propostas, mas os rotarianos têm uma prática

\footnotetext{
40 Sobre a dimensão antipolítica do desenvolvimento, veja FERGUSON, James. A máquina anti política: desenvolvimento, despoliticização e poder burocrático no Lesoto. Minneapolis: Minnesota University Press, 1994

${ }^{41}$ COMAROFF, Jean e COMAROFF, John. "Capitalismo milenar: primeiros pensamentos sobre a Segunda Vinda" In: COMAROFF, J. e COMAROFF, J. (orgs). Capitalismo milenar e cultura do neoliberalismo. Durham/Londres: Duke University Press, 2001 , p. 10 e 15.

42 Também conhecido como Konza City, este terreno baldio no país de Kamba, perto da estrada que liga Nairobi a Mombasa, é cotado a se tornar o grande parque tecnológico do Quênia cujos plantas dos arranha-céus serão diretamente inspirados naqueles de Dubai. No entanto, o projeto estaria hoje muito comprometido devido à aposentadoria de seu principal investidor (http://www.konzacity.co.ke).
}

${ }^{43}$ Notas de campo, 9 de dezembro de 2011. 
religiosa muito diversa ${ }^{44}$. Vários deles afirmam não ser um crente devoto ou que nunca vai à igreja. Outros são muito crentes e tem uma prática religiosa regular. Entre eles, muitos frequentam a Capela de Nairobi, na Ngong Road, ou sua subsidiária, a Igreja Mavuno, que, apesar de exibir uma série de semelhanças com as Igrejas pentecostais, não se identificam como tais. Animadas por pastores treinados nos Estados Unidos e oferecendo uma série de sermões sobre o sucesso econômico e individual, a consagração profissional e financeira, eles são típicos do que Gifford chamou de cristianismo da classe média, se quisermos bem entender que "classe média" é principalmente uma declaração despolitizadora e teleológica ${ }^{45}$. Nesse sentido, os Rotary clubes são principalmente instituições seculares que mantêm com as igrejas afinidades eletivas que caem tanto no domínio da homologia discursiva quanto no parentesco prático. Por exemplo, a Capela de Nairobi é, da mesma forma que um clube, uma instituição burocrática que acolhe os fiéis que também são membros e tem seus nomes na lista. As relações de orientação que ela organiza, apesar de sua finalidade, são bastante próximas em sua forma das relações do conselho que encontramos nos clubes. Nesse sentido, as disposições seculares dos membros do Rotary às vezes ressoam como uma atividade religiosa, que o clube revive e mantém ${ }^{46}$.

O que o Rotary Club de Langata e sua sociabilidade particular mostram é a formação - algumas ainda embrionárias - de um campo econômico no Quênia, dos quais os agentes, os profissionais liberais, os executivos corporativos e a comunidade empresarial, compartilham o mesmo habitus de acumulação econômica e prevenção da política. Esta disposição, modelada durante os anos de predação do regime Moi e consolidada pelos excessos do regime de Kibaki que o sucedeu, levou os membros do clube a criticar não uma facção dominante, mas as práticas políticas que prejudicaram seus interesses. À primeira vista, parece que os relacionamentos gerenciais e apolíticos dos assuntos públicos promovidos pelos rotarianos dificilmente se impuseram: muitas tentativas de mediação e apaziguamento durante a crise eleitoral de 2007-2008 pareciam ridículas diante das milícias partidárias e dos massacres rurais atiçados por anos de disputas de terras.

\footnotetext{
${ }^{44}$ Cada igreja possui suas práticas variáveis e ambivalentes. Sobre a reversibilidade destas práticas religiosas quanto sobre a variedade de suas raízes culturais, ver DORZ, Yvan. "As origens vernaculares do sonho pentecostal no Quênia: conversão, cura, mobilidade social e política". In: CORTEN, André e MARY, André (orgs). Imaginários políticos e pentecostalismo. África/América Latina. Paris: Karthala, 2000, p. 81-101.

45 Sobre a Capela de Nairobi, consultar GIFFORD, Paul. Cristianismo e vida pública no Quênia. Londres: Hurst \& Co., 2009, p. 110112.

${ }^{46}$ Sobre o clube como emanação da seita protestante, consultar:

WEBER, Max. "Seitas protestantes e o espírito do capitalismo", in A Ética Protestante e no Espírito do Capitalismo. Paris: Gallimard, 2003 (1905).

Maurice Agulhon descreve, no entanto, um fenômeno mais complexo através do desaparecimento das confrarias a partir do século XVIII, tanto pela captura de parte de suas funções pelas autoridades municipais quanto pela competição de filantropia secular e, mais tarde, vida de associação. AGULHON, Maurice. Penitentes e francos maçons na antiga Provence. Paris: Fayard, 1968, p. 41, 85.
} 
No entanto, essa atitude de evasão, impulsionada por discursos liberalizados e globalizados, gerou lucros simbólicos para aqueles que foram socializados através de instituições tais como os Rotary Clubs. Para os jovens membros de Langata, herdeiros da elite Kikuyu originária da independência ou do antigo Regime Moi, a caridade dos clubes e a promoção de novos valores no Quênia permitiram uma forma de clareamento dinástico, de maquiagem das origens da riqueza familiar, da legitimação de seu status econômico. Os meios pelos quais suas fortunas foram adquiridas hoje seria condenada, a sociabilidade rotariana esconde os legados financeiros mais duvidosos dos autores da respeitabilidade e do mérito.

Além disso, as eleições gerais de 2013 mostraram que o discurso gerencial agora poderia constituir um capital político. A campanha do dirigentes de empresas como Evans Kidero, CEO de longa data da empresa açucareira Mumias e agora Governador de Nairobi, do financista Jimnah Mbaru, seu infeliz concorrente, do advogado Mutula Kilonzo Junior, que herdou do seu pai falecido o assento do senador de Makueni, mostra que as liberalizações tem feito, no fim, do empresário, do profissional, do grande chefe, as figuras de autoridades políticas legítimas frente aquela do "político" tradicional, conhecido tribalista e corruptos. Nesse sentido, os rotarianos também conseguiram se fazer reconhecer como os intermediários legítimos das políticas e dos padrões neoliberais no Quênia. Eles fizeram da Aliança do Setor Privado do Quênia, um grande sindicato do setor privado fundado por rotarianos, o interlocutor obrigatório do governo para o desenvolvimento de políticas econômicas. Não se trata apenas de uma estratégia de acesso ao Estado, o uso deste discurso liberal não é simplesmente utilitário. A sociabilidade do rotariano mostra que ele alimenta as aspirações sociais de uma parte da elite, suas categorias de entendimento político. Ela também molda um "tipo de homem" nascido do neoliberalismo e das privatizações ${ }^{47}$. Na "abjecção" pela qual a globalização retorna a África e aos africanos, estes novos homens carregam a "promessa de uma inclusão"48 a uma ordem mundial libertadora das servidões do presente.

\footnotetext{
${ }^{47}$ A expressão "tipo de homem de privatização" é derivada da noção de Menschentum (tipo de homem) de Max Weber. BAYART, Jean-Françoi. "Foucault au Congo". In: GRANJON, Marie-Christine (org). Pensando com Michel Foucault. Teoria crítica e práticas políticas. Paris: Karthala, 2005, p. 219.

48 Expressão de Rita Abrahamsen, "O Poder das Parcerias na Governança Global". In: Third World Quaterly, 25 (8), 2004, p. $1453-$ 1467; veja também, em um registro comparável, HARRISON, Graham. "Pos-condicionalidade política e reforma administrativa: reflexões sobre os casos de Uganda e da Tanzânia". In: Development and Change, 32 (4), 2001, p. 657-679.
} 


\section{Algumas propriedades sociais dos membros mais ativos do Rotary Club of Langata (2008-2011)}

\begin{tabular}{|c|c|c|c|}
\hline & Ensino Médio & Ensino Superior & Profissão \\
\hline Ed. Mugo* & Starehe Boys & $\begin{array}{l}\text { Universidade de Nairobi } \\
\text { (UoN) }\end{array}$ & Arquiteto, Agrimensor de Quantidade \\
\hline Alex Nyaga* & & $\begin{array}{l}\text { Les Roches Int. Scholl } \\
\text { (Suiça) }\end{array}$ & Limpeza de parapeitos (limpeza industrial) \\
\hline Antoinette Absaloms & & UoN (Direito) & Diretora Geral, Unilever \\
\hline Mercy Mutua* & & Warnick, Michigan State & Agente de investimento, Finance Partners \\
\hline Nick Bore & Nairobi School & $\begin{array}{l}\text { Moi University } \\
\text { (Engenharia) }\end{array}$ & Comerciante (produtos pretolíferos, Vitol) \\
\hline June Gachui* & St Mary's & LSE (Direito), Washington & Advogada (propriedade intelectual) \\
\hline Janet Onyang'o & & $\begin{array}{l}\text { Queen Mary Londres, } \\
\text { Warnick }\end{array}$ & Jornalista (BBC) \\
\hline Oscar Njuguna & Nairobi School & $\begin{array}{c}\text { United States } \\
\text { International University } \\
\text { (USIU) }\end{array}$ & Administrador, Kenchick \\
\hline George Ikua & Alliance & UoN (Administração) & Consultor de gestão \\
\hline Moses Muriithi & Alliance & Buckingham, Manchester & Diretor, promotor imobiliário (Evergreen) \\
\hline Georges Masese & Lenana & Uon (Direito) & Conselheiro jurídico, E.A Growers \\
\hline Muchau Githiakia & Lenana & Strathmore & Diretor Geral, Izon Future Systems (NTIC) \\
\hline Mutula Kilonzo Jr* & Machakos & Nagpur (India, Direito) & Advogado \\
\hline Marion Karanja & State House Girls & UoN (Direito) & Advogado \\
\hline Carole Kariuki & & $\begin{array}{c}\text { Bowling Green State U. } \\
\text { (USA, Administração } \\
\text { Pública) }\end{array}$ & Administrador e depois P-GD, KEPSA \\
\hline A.K.Maina & & UoN (Direito) & Diretor Geral, Kenya Railways \\
\hline Hinga Waiyaki* & & UoN (Direito) & Advogado (negócios) \\
\hline Peter Warutere & & $\begin{array}{c}\text { UoN, Manchester, } \\
\text { Maastricht (Economia) }\end{array}$ & $\begin{array}{l}\text { Patrão, Agrimensor de Quantidade, Archbill } \\
\text { Consultants (imobiliário) }\end{array}$ \\
\hline Peter Kariuki & Nairobi Scholl & UoN (Economia) & Gabinete de Comunicação, Banco Mundial \\
\hline Maina S. Gichohi* & Lenana & UoN (Administração) & Administradora Reginal, TNT East Africa \\
\hline Beryl Ouma & Alliance Girls & Shivaji (India, Direito) & Advogado \\
\hline Sailepu Montent & St Mary's & Leicester, LSE & $\begin{array}{l}\text { Assistente do Administrador Regional do Banco } \\
\text { Barclays }\end{array}$ \\
\hline Sarah Migwi & St Mary's & $\begin{array}{l}\text { USIU (Administração } \\
\text { Internacional) }\end{array}$ & $\begin{array}{l}\text { Diretora geral, Protel Studios (estúdio de TV, } \\
\text { publicidade) }\end{array}$ \\
\hline Catherine Gachie & St Mary's & USIU (Administração) & Consultora de Gestão (hotelaria) \\
\hline Irene Wamakau & & UoN (Direito) & Conselheira jurídica, Banco Barclays \\
\hline Githuku Mwangi & & UoN (MBA) & Conselheiro PME, International Finance Corporation \\
\hline Nashon Omondi & & Kenya Polytechnic & Engenheiro, consultor NTIC (hotelaria) \\
\hline Anthony Wachira & & $\begin{array}{l}\text { Moi University, USIU } \\
\text { (MBA) }\end{array}$ & $\begin{array}{l}\text { Administrador para o Quênia, GRUNDFOS (bombas } \\
\text { hidráulicas) }\end{array}$ \\
\hline Joe Musangi & Lenana & USIU & Gerente, Hospitality Systems Consulyants \\
\hline Andrew Githaiga & St Mary's & McGill (Can.) & Administrador geral, Mlima House (banco) \\
\hline Nathalie Ngatia & St. Austins & Manchester, USIU (MBA) & Administradora, Banco Standard Chartered \\
\hline Grace Mucheru & & & Comissária, Kenya Revenue Authority \\
\hline Isaac Wanjero & Lenana & Jomo Kenyatta University & $\begin{array}{l}\text { Conselheiro, NTIC Commonwealth Development } \\
\text { Corp. }\end{array}$ \\
\hline Matilda Kobia & & $\begin{array}{l}\text { Catholic University. } \\
\text { Strathmore }\end{array}$ & Administrador Banco Barclays \\
\hline Nancy Kanyago* & Hillcrest & Reading, Leeds (Direito) & $\begin{array}{l}\text { Conselheiro jurídico do Plano Internacional do } \\
\text { Quênia }\end{array}$ \\
\hline Benjamin Muatha & Starehe Boys & Moi University (NTIC) & $\begin{array}{l}\text { Responsável do sistema de informação do Housing } \\
\text { Finance }\end{array}$ \\
\hline Cyprian Nyamwamu* & & $\begin{array}{l}\text { UoN (Ciências Políticas) } \\
\text { Kenyatta (Administração } \\
\text { Pública) }\end{array}$ & $\begin{array}{l}\text { Diretor Naciona da Convenção do Conselho } \\
\text { Executivo (NCEC) }\end{array}$ \\
\hline
\end{tabular}




\begin{tabular}{|l|c|c|l|}
\hline Gitau Gikonyo & & UoN (Direito), Botswana & Advogado \\
\hline Hilda Nduta & UoN (Direito) & Diretora, Golf Fore Africa, Tidy Masters (limpeza) \\
\hline Janet Kanini & Kenyatta (Com.) & Apresentadora de TV (NTV) \\
\hline Sam Gichuru & & Stratmore, Daystar (NTIC) & Diretor Executivo, NaiLab (incubadora NTIC) \\
\hline Serah Njoroge & $\begin{array}{c}\text { Egerton (Agri.), USIU } \\
\text { (MBA) }\end{array}$ & $\begin{array}{l}\text { Consultor de facilidades de infraestruturas pública- } \\
\text { privada, Banco Mundial }\end{array}$ \\
\hline
\end{tabular}

Eu mencionei aqui os membros mais presentes nas reuniões durante o período do meu estudo. São marcados com um * (asterisco) os rotarianos cujos pais são membros do Rotary, em geral dos clubes de Nairobi Norte. Essas informações foram coletadas por entrevistas (E. Mugo, A. Nyaga, M. Mutua, N. Bore, J. Gachui, M. Muriithi, M. Karanja, C. Kariuki, A. K. Maina, M. S. Gichohi, G. Mwangi.), através do perfil do Facebook dos membros com os quais eu estava conectado, e complementados através aos sites como o Linkedln. A precisão quanto à data de entrada no clube é enganosa: certos membros têm frequentado o clube há tempo antes de se unirem formalmente, sua mobilidade profissional era incompatível com a exigência da presença semanal. Finalmente, muitos rotarianos de Langata tem pais originários de diferentes regiões, por isso é em vão precisar sua pertença étnica. 